\title{
Leveraging dynamic decision-making and environmental analysis to support authentic learning experiences in digital environments
}

\author{
Aprovechar la toma de decisiones dinámica y el análisis ambiental para \\ respaldar experiencias de aprendizaje auténticas en entornos digitales
}

\author{
Jill Stefaniak \\ University of Georgia. Athens, USA \\ jill.stefaniak@uga.edu \\ Meimei Xu \\ University of Georgia. Athens, USA \\ meimei.xu@uga.edu
}

\begin{abstract}
Authentic learning is a pedagogical approach that situates students in real-world settings. It thereby requires instructional designers to make contextualized design decisions to enhance students' online learning experiences. The purpose of this paper is to provide instructional designers with a conceptual framework to help guide their instructional design decisions for authentic learning experiences in digital environments. We purport that these design decisions should be guided by three constructs: environmental analysis, dynamic decisionmaking, and promotion of knowledge acquisition. We also provide recommendations for future research on decision-making practices and processes in instructional design contexts.
\end{abstract} Keywords: authentic learning, environmental analysis, decision-making practices, instructional design, online instruction.

\section{Resumen}

El aprendizaje auténtico es un enfoque pedagógico que sitúa a los estudiantes en entornos del mundo real. Por lo tanto, requiere que los diseñadores instruccionales tomen decisiones de diseño contextualizadas para mejorar las experiencias de aprendizaje en línea de los estudiantes. El propósito de este artículo es proporcionar, a los diseñadores instruccionales, un marco conceptual para ayudar a guiar sus decisiones de diseño instruccional para experiencias de aprendizaje auténticas en entornos digitales. Pretendemos que estas decisiones de diseño deben estar guiadas por tres constructos: análisis ambiental, toma de decisiones dinámica y promoción de la adquisición de conocimientos. También proporcionamos recomendaciones para futuras investigaciones sobre prácticas y procesos de toma de decisiones en contextos de diseño instruccional.

Palabras clave: aprendizaje auténtico, análisis ambiental, prácticas de toma de decisiones, diseño instruccional, instrucción en línea.

RED. Revista de Educación a Distancia. Núm. 64, Vol. 20. Artíc. 3, 30-09-2020

DOI: http://dx.doi.org/10.6018/red.412171 
Authentic learning is an educational approach that involves real-world problems and projects to support student learning (Herrington \& Oliver, 2000). It emphasizes the role of authenticity and situated learning in the student learning process. The main premise of authentic learning is to expose learners to authentic contexts that demonstrate how knowledge is used in the real world (Herrington et al., 2014).

Herrington and Oliver (2000) have suggested that this can be accomplished by providing authentic activities that reflect real world experiences, provide multiple roles and perspectives, support collaborative construction of knowledge, and support learners' abilities to reflect and articulate their actions to recognize the emergence of tacit knowledge. Callison and Lamb (2004) added additional criteria to define authentic learning, including inquiry-based learning pedagogy, out-of-school resources, student collaboration and authentic assessment of the student learning process. Rule (2006) analyzed the literature of authentic learning in different disciplines. The findings demonstrated that using real-world settings in student learning tasks strengthened their ability to retain and apply knowledge. In addition to authentic situated learning environments, open-ended inquiries, collaborative activities, and self-directed learning processes of students are also regarded as essential components in the framework of authentic learning.

With the continuous growth of digital technologies influencing instruction, researchers have explored means for integrating authentic learning activities in online environments (Broadbent \& Poon, 2015; Kim et al., 2014; Parker et al., 2013; Rashid \& Asghar, 2016; Sanga, 2017). Herrington et al. (2007) confirmed the development of immersive learning technologies in the form of virtual reality, from which training experiences in education, military, aviation, and medical learning can be enhanced. Parker et al. (2013) conducted design-based research in higher education contexts to explore how authentic online learning can be developed to benefit higher education practitioners. Recent studies, such as Lau and Tasir (2018), discussed the design and development of an online authentic learning environment to support learning inferential statistics. To date, limited research has been done to investigate the design of online authentic learning opportunities (Spector, 2018). As more instructional designers (IDs) shift to design online authentic learning experiences, additional supports are needed to help inform their decisionmaking practices as they account for environmental factors that will greatly impact their learners' acquisition of knowledge.

\section{Purpose of Paper}

Researchers have suggested that more research is needed to examine the decision-making processes associated with instructional design practices (Stefaniak et al., 2018; Jonassen, 2012; Kopcha et al., 2020). Recognizing that IDs are often required to design solutions within time constraints, dynamic decision-making prompts instructional designers to make decisions within a short time frame (Klein, 2008).

Leveraging dynamic decision-making and environmental analysis to support authentic learning experiences in digital environments. Jill Stefaniak \& Meimei Xu. 
While studies have focused on the types of decisions and judgments made by IDs (Stefaniak \& Tracey, 2014; Ertmer et al., 2008; Gray et al., 2015), little has been done to theoretically ground these decision-making behaviors in an instructional design context. Researchers have suggested that IDs need to apply a flexible mindset when engaging in illstructured problem-solving practices for real-world contexts (Yanchar \& Gabbitas, 2011). Decisions that are made by IDs reflect their perception of the context (Barsalou, 2015; Kopcha et al., 2020). This calls for them to be aware of contextual factors contributing to the learning space. It is inevitable that time constraints will impede an IDs' abilities to make appropriate design decisions (Tessmer \& Wedman, 1990; Yanchar \& Hawkley, 2014); thus, we highly advocate for them to conduct environmental analyses to inform their instructional design decisions. It also requires them to be self-aware of their influence on the instructional design process (i.e. prior knowledge, design experience, and personal assumptions).

The purpose of this paper is to proffer a conceptual framework in support of the instructional design of authentic learning experiences in digital environments through three constructs: environmental analysis (localization of context, acknowledgement of orienting factors, and perception of utility); dynamic decision-making (establishing a bounded rationality, ability to conjecture, and alignment of design solutions); and promotion of knowledge acquisition (conceptual, strategic, and conditional knowledge; time sensitive instruction, and situated activities in context). Each of these constructs and their subcomponents are discussed in the remainder of this paper.

While this framework is applicable to all types of learning environments (i.e. face-to-face, hybrid, blended), examples will focus on how these constructs work in concert to support authentic learning experiences in digital environments. While every digital learning experience is different, IDs must determine the extent of interaction that will occur between learner-to-learner, learner-tocontent, and learner-to-instructor (Richardson et al., 2017). IDs can leverage outputs of an environmental analysis to support their dynamic decision-making as they design learning experiences that are situated and promote acquisition of knowledge and transfer of learning in a digital environment.

\section{Conceptual Framework}

As shown in Figure 1, dynamic decision-making can be leveraged to align environment analysis and knowledge acquisition through an ID's ability to establish a bounded rationality, engage in design conjecture, and align decision solutions. The overarching umbrella of environmental analysis involves the localization of context, acknowledgement of orienting factors, and supporting perceptions of utility to determine the appropriate degree of interaction required of the learning experience. Learners' acquisition of knowledge is supported through learning activities that elicit demonstration of their conceptual, strategic, and conditional knowledge domains, time-sensitive instruction, and situating activities in context.

Leveraging dynamic decision-making and environmental analysis to support authentic learning experiences in digital environments. Jill Stefaniak \& Meimei Xu. 


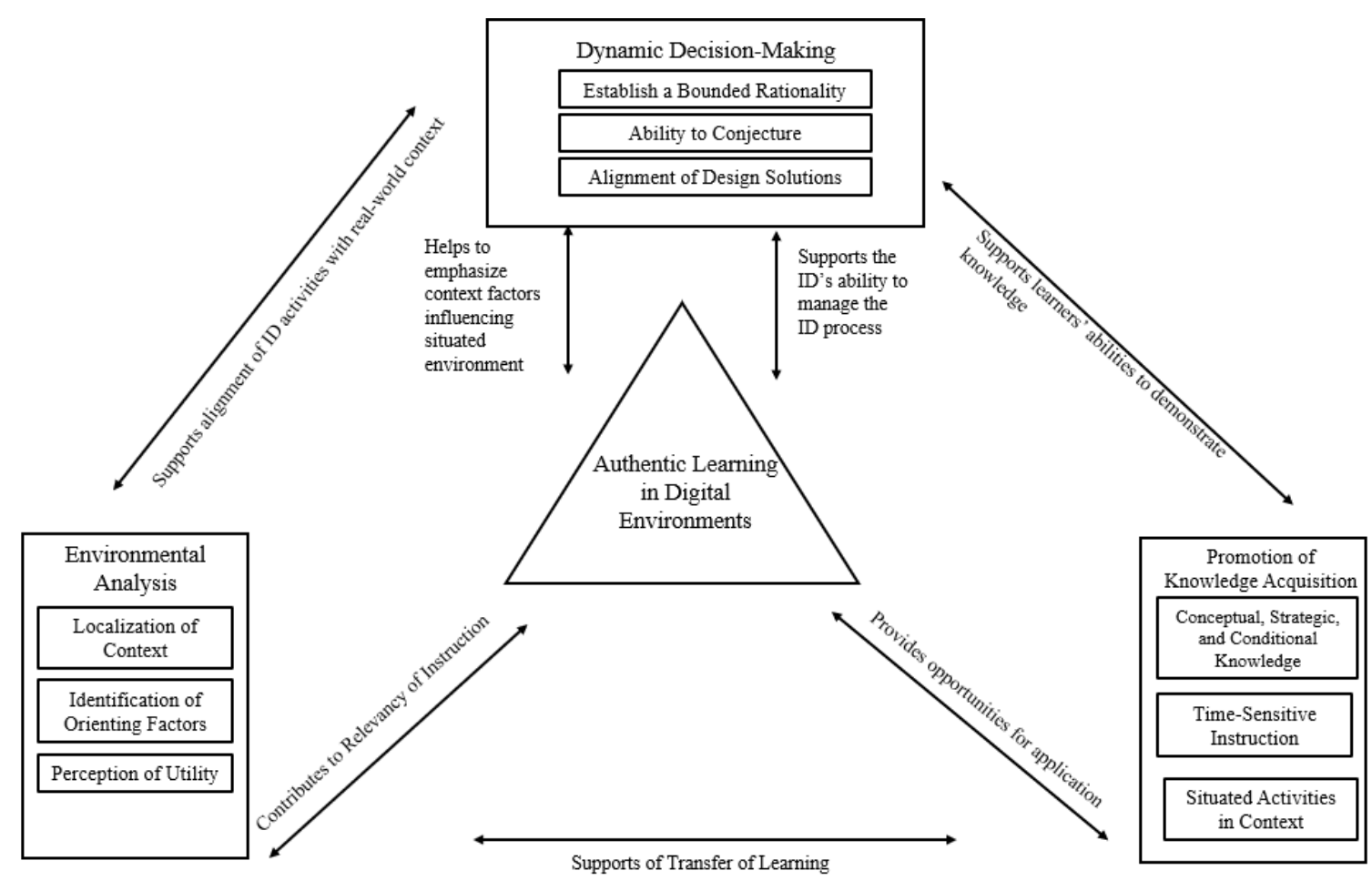

Figure 1. Conceptual framework to leverage dynamic decision-making and environmental analysis to support authentic learning in digital environments

\section{Environmental Analysis}

Environmental analysis is defined as "the analysis of the context in which the instructional product will be employed, of the physical and use factors of the instructional environment and its support environment" (Tessmer, 1991, p. 9). While environmental analysis is recognized as being an important component of the instructional design process, Tessmer (1990) expressed concerns that it is often neglected in the instructional design process. This concern holds true today as many instructional design models do not sufficiently address environmental analysis nor emphasis on needs assessments expanding beyond a basic learner analysis (Stefaniak, 2020a, 2021). The results of these analyses pose significant implications for the design of learning experiences, particularly tacit knowledge that may greatly influence a learner's acquisition of knowledge and ability to transfer their knowledge and apply it in real-world settings.

Four premises emerge from Tessmer's work on context that are relevant to how instructional designers conceptualize design decision-making practices for authentic learning experiences in online environments:

1. Most of the research on context has emphasized exploring how the products are being used rather than the process of how they are designed.

Leveraging dynamic decision-making and environmental analysis to support authentic learning experiences in digital environments. Jill Stefaniak \& Meimei Xu. 
2. Contextual and environmental analyses place greater emphasis on understanding how instruction can be applied in the real world.

3. Environmental analysis should be conducted as a component of front-end analysis.

4. Learners must perceive utility in the instructional activities they are required to complete.

Recognizing environmental analysis as one of the driving forces behind this conceptual framework helps emphasize the arguments that the environmental analysis of contextual factors needs to be prevalent in the instructional design process and incorporated earlier when designing instruction, preferably during the needs assessment phase (Tessmer, 1990, 1991; Tessmer \& Wedman, 1995). This argument further supports Kopcha et al.'s (2020) premise that additional exploration is needed on design process versus product and Stefaniak's (2021) position that IDs need to be trained on how to integrate needs assessment and analysis into their design activities.

Environmental analysis places additional attention on exploring how knowledge will be applied in real-world settings (Tessmer \& Richey, 1997); thus, informing the design of authentic learning experiences. The information gathered on contextual factors influencing learners, the instructional environment, and the transfer environment ultimately impact the types of decisions, strategies, and solutions an instructional designer may employ during a project. Taking a recursive approach to weaving environmental analysis throughout the instructional design process enhances IDs abilities to design an authentic learning experience that increases their learners' perceptions of utility as it relates to the transfer of their newly acquired knowledge to real-world contexts.

\section{Localization of Context}

Contextual analysis is a term referred to among IDs to describe the process of accounting for contextual factors that may support or inhibit learning (Richey \& Tessmer, 1995) and falls under the overarching category of environmental analysis (Tessmer \& Wedman, 1995). In their seminal publication exploring the role of context in instructional design, Tessmer and Richey (1997) suggested that IDs must approach context through three paradigms: the orienting context, instructional context, and transfer context. The goal is for them to design instructional solutions that demonstrate alignment of considerations among these three contexts (Tessmer \& Richey, 1997).

For example, as an ID begins developing an authentic learning experience to be facilitated in a digital learning environment and conducts an environmental analysis, employing a localized approach to identifying contextual factors will help them contend with time constraints often associated with conducting environmental analyses (Meloncon, 2017). Localizing the context would enable them to identify parameters for the type of factors that may influence designing and facilitating the learning activity and supporting learners' abilities to transfer these skills to a realworld environment. To expedite the amount of time spent on the environmental analysis, the ID may focus on the contextual factors that are directly linked to the learning experience and exclude factors that may impact the situation at the periphery. Adopting a scaled and localized approach to

Leveraging dynamic decision-making and environmental analysis to support authentic learning experiences in digital environments. Jill Stefaniak \& Meimei Xu. 
analysis also aligns with the concept of establishing a bounded rationality during decision-making that will be discussed later in this paper.

\section{Identification of Orienting Factors}

While it is important for instructional designers to consider the three contextual paradigms (orienting, instructional, and transfer) when designing instruction, failure to adequately gather sufficient information pertaining to orienting factors can greatly influence the quality of the instructional experience. Orienting factors address preexisting conditions that exist in the organization and/or environment. Examples of orienting contextual factors include learners' prerequisite skills, attitudes toward training, organizational culture as it relates to training practices (Tessmer \& Richey, 1997).

Orienting factors focused on the learning audience help IDs develop a learner analysis and profile that can be referred to throughout the design process. Additionally, other orienting factors focused on preexisting conditions in the organization (i.e. business or school) may also shed light regarding tacit information learners should be aware of during the learning experience. This is particularly important when designing authentic learning experiences in that the learning environment should help learners' articulate their understanding of the content and environment to enable tacit knowledge to be made explicit (Herrington \& Oliver, 2000, p. 26). This also supports the need for IDs to elicit demonstrate of multiple knowledge domains as discussed later in this paper.

\section{Perception of Utility}

The instructional context addresses the delivery of instruction. This contextual lens accounts for instructional delivery platforms (i.e. face-to-face instruction, blended instruction, online instruction) as well as learner and instructor expectations. The transfer context accounts for exploring where the learners will be applying (or transferring) the knowledge acquired during training. A learner's perception of utility supports his or her ability to transfer newly acquired knowledge to a real-world context.

To date, digital learning environments have been recognized for offering many affordances that promote the development of $21^{\text {st }}$ century learning skills such as problem-solving, design thinking, and creativity (Greenhow et al., 2009; Partnership for $21^{\text {st }}$ Century Learning, 2016). Furthermore, digital environments can provide learning space to allow for learners to take more autonomy in their own learning experience (AlManun et al., 2020; Cui et al., 2013; Gillett-Swan, 2017; Jenkins et al., 2009; Nacu et al., 2018).

In a study exploring instructional strategies to support the transfer of learning from online environments to real-world contexts, Stefaniak (2020b) offered strategies and resources that can increase learners' perceptions of utility and perceptions of available resources. Aligning the

Leveraging dynamic decision-making and environmental analysis to support authentic learning experiences in digital environments. Jill Stefaniak \& Meimei Xu. 
expectations of instructional activities with learners' competencies, communicating expectations related to learner autonomy in an authentic learning environment, and designing instructional experiences that accommodate flexibility to adapt to contextual factors are various actions that instructional designers can take to support learners' perceptions of utility.

The use of learning management systems and communication systems to promote interaction among learners are other examples of increasing a learner's perception of available resources (Greenhow et al., 2009; Martin et al., 2016; Nacu et al., 2018; Richardson et al., 2017; Stefaniak, 2020b). These digital tools, in concert with activities that promote interaction, provide a level of social support needed to support the transfer of knowledge to a real-world context. As learners complete activities that challenge their ability to demonstrate knowledge acquisition related to the strategic and conditional domains (Stark et al., 2011), it is imperative that the instructional designers embed coping strategies to support learners' abilities to apply knowledge and alleviate challenges as the learner moves from the digital environment to the real-world environment permanently. The decisions required of an ID to provide coping mechanisms are dependent of the unique environmental conditions influencing the authenticity of the learning experience, the level of complexity associated with the project, and the learners' and instructional designer's prior experience (Stefaniak, 2020b).

\section{Promotion of Knowledge Acquisition}

Learners are more apt to successfully demonstrate learning transfer if they are provided with opportunities to demonstrate and apply their knowledge. Their ability to successfully transfer their newly acquired knowledge is largely dependent on their understanding of contextual factors influencing the real-world environment. It is imperative that IDs are able to scale contextual factors to create a localized context that is easier for their learners to navigate as well as ensure learners' understand the learning affords and constraints associated with scaling contextual factors to create a learning environment that is conducive to applicable.

Learners need to interact with the instructional material (Ertmer et al., 2011). This can be achieved through assigned readings, and course assignments that elicit a demonstration of knowledge acquisition. Discourse among peers in the online environment can also provide students with an opportunity to engage in conversations about how instructional concepts may be internalized and interpreted depending on individuals' previous experiences and prior knowledge (Ertmer \& Koehler, 2014; Richardson et al., 2013).

Designing authentic learning experiences in an online learning environment warrants strategic decision-making on behalf of the ID to support the learning experience and provide the necessary support to the learning audience (Garcia-Cabrero et al., 2018; Spector, 2018). Several studies have been conducted to explore various instructional strategies to promote authentic learning experiences in online learning environments (Anak Marcus et al., 2018; Lai et al., 2017; Keengwe \& Kidd, 2010; Luo et al., 2018). These studies have acknowledged that instructional

Leveraging dynamic decision-making and environmental analysis to support authentic learning experiences in digital environments. Jill Stefaniak \& Meimei Xu. 
designers face additional challenges when designing authentic learning experiences for an online environment. These challenges include helping students transition from the online learning environment to the application setting, identifying means to facilitate authentic learning experiences through asynchronous and synchronous online environments, and providing feedback to students for their performance in authentic learning activities.

\section{Conceptual, Strategic, and Conditional Knowledge}

Paris et al. (1983) categorized knowledge according to three domains: conceptual, conditional, and strategic to assist educators in selecting appropriate instructional strategies to support students learning how to read. These domains were later revisited by Stark et al. (2011) to identify different instructional strategies to support adult learners. They defined conceptual knowledge as declarative knowledge about concepts related to the subject matter. Strategic knowledge elicits an individual's ability to engage in problem-solving, and conditional knowledge takes into consideration one's ability to address contextual factors when applying conceptual knowledge in a real-world situation.

IDs need to determine the extent that each of these three knowledge domains is to be addressed during an authentic learning activity. If the topic is relatively new to a group of learners, there may be instances where greater emphasis is placed on declarative knowledge. A more advanced activity may require learners to demonstrate strategic knowledge as it relates to a realworld setting.

Once IDs have identified the goal of the learning activity according to the three knowledge domains, they may then begin to pair instructional strategies accordingly. Several taxonomies are recognized for classifying various types of learning (i.e. Bloom, 1956; Gagne, 1964; Gagne \& Merrill, 1990; Merrill, 1999). Each of these taxonomies guides the selection of instructional strategies that increase in complexity as well as identify different conditions that may warrant one strategy over another.

Sentz and Stefaniak (2019) suggested that additional support is required when a learner is familiarizing oneself with conceptual knowledge. Instructor support is gradually reduced as the learner demonstrates their abilities to apply strategic and conditional knowledge. The goal of promoting authentic learning experiences is for a learner to demonstrate and apply conditional knowledge to any given situation (Yanchar et al., 2010).

To support the transfer of learning to real-world contexts, the online learning experience should incorporate strategies and activities that task the learner with demonstrating their acquisition of conceptual, strategic, and conditional knowledge domains as they relate to the subject matter. If the goal of instruction is for the learner to demonstrate resilience by applying what they learn to a variety of real-world situations, they must be provided opportunities to observe and experience learning experiences that elicit the application of strategic and conditional knowledge (Herrington, 2006). These two knowledge domains are dependent on the learner's

Leveraging dynamic decision-making and environmental analysis to support authentic learning experiences in digital environments. Jill Stefaniak \& Meimei Xu. 
ability to adapt to various contextual factors that may influence the authentic situation (Sentz \& Stefaniak, 2019).

\section{Time-Sensitive Instruction}

Several studies exploring the complexities faced by IDs recognize that time constraints greatly impact an instructional designer's ability to make appropriate decisions and implement solutions when designing instruction (Baaki, 2018; Rabel, 2019; Sentz et al., 2019; Tessmer \& Wedman, 1990; Yanchar \& Hawkley, 2014; Yanchar et al., 2010). Several studies that have explored strategies employed by IDs in real-world contexts have drawn attention to the need for them to be provided with strategies to support problem-solving and decision-making that occur throughout the instructional design process (Boling et al., 2011; Gibbons, 2003; Gray et al., 2015; Nelson \& Stolterman, 2000; Yanchar \& Gabbitas, 2011; Yanchar et al., 2010; Zhu et al., 2020). A response to this need will position IDs to strategically leverage instructional theory and the abovementioned instructional taxonomies to customize timely solutions that align with the unique conditions present in any given situated environment. Additionally, this provides further support for the need to localize context when designing instruction.

\section{Situated Activities in Context}

Authentic learning tasks situated in real-world settings can provide instructional designers with learning opportunities to transfer knowledge (i.e. conceptual, strategic, and conditional) into real-world practices (Herrington \& Parker, 2013). Authentic learning activities within online environments have been regarded as beneficial for instructional designers to grasp technology influences (i.e., online environments) on instructional design and student learning outcomes (Greenhow et al., 2009; Nacu et al., 2018; Herrington et al., 2003).

Learners can be supported in these situated activities through a variety of strategies that elicit collaborative construction of knowledge, promote reflective practice, and utilizes coaching and scaffolding techniques imposed by the instructor (Ertmer \& Cennamo, 1995; Nacu et al., 2018; Sharma \& Hannafin, 2004; Stefaniak, 2017). It is important for IDs to consider how a learner is engaging with the instructional materials, their peers, and instructor throughout the learning experience, and this greatly impacts their perceptions of utility and abilities to apply knowledge to real-world settings.

Authentic learning provides experiences that expose learners to contextual factors that may contribute to or inhibit performance. These experiences are guided by contextual factors that are relevant to the subject matter and trends in the field. The use of contextual analysis as a construct for this framework provides the impetus for exploration of how the learner adapts to different contextual factors that may influence their application of conceptual, strategic, and conditional knowledge (Sentz \& Stefaniak, 2019). In turn, the real-world experiences derived from authentic

Leveraging dynamic decision-making and environmental analysis to support authentic learning experiences in digital environments. Jill Stefaniak \& Meimei Xu. 
learning provide learners with an opportunity to explore the effects that different contextual factors may pose for the learning environment. For example, students may gain a better understanding of the logistics involved when implementing solutions in different environments and organizations that include many stakeholders. This supports the perspective that instructional design is an iterative and evolving process as IDs leverage their skillsets, environmental conditions, and contextual factors influencing the learning experience (Boling et al., 2011; Gibbons, 2003; Yanchar \& Gabbitas, 2011).

\section{Dynamic Decision-Making}

IDs are called to make decisions often as they work and maneuver through design space (Jonassen, 2012). The scope of their decisions can range from decisions in the analysis and planning phase of a project, designing interventions, implementation, and utilizing evaluative instruments to measure outcomes and performance; all of which contribute to promoting and eliciting conceptual, strategic, and conditional knowledge. Some questions, routine in nature, may focus on what type of design document to use as a blueprint for a project, determining what types of information are needed to conduct a formative or summative evaluation, or what types of technological applications (i.e. software) should be utilized in an intervention.

Decision-making is a process that has been conceptualized as a cognitive process consisting of a selection of beneficial options from a larger set of choices (Jonassen, 2010). Multiple decision-making frameworks have been developed to guide decision-making processes in different contexts and disciplines (Table 1). Decision-making models and frameworks can be classified into two major types: rational decision-making and dynamic or naturalistic decisionmaking. Rational decision-making emphasized a series of actions that contain strategic analytic processes and a comparison of multiple options (De Martino, Kumaran, Seymour, \& Dolan, 2006). Dynamic or naturalistic decision-making, on the contrary, involved instructional designers to make prompt decisions within a short time frame (Klein, 2008). A dynamic decision-making process requires IDs to have a complete awareness of factors that may contribute to their learners' ability to transfer knowledge from the learning environment to a real-world environment. Examples of these factors include their knowledge (i.e. conceptual, strategic, and conditional) and contextual variables with time constraints.

\section{Establish a Bounded Rationality}

The concept of decision-making within a bounded rationality was first introduced by Simon (1957) when he discussed the challenges that decision-makers face when solving illstructured problems. Simon purported that decision-makers operate within a bounded rationality where they rationalize their decisions based on what they already know about the situation or topic, their previous experience, and assumptions that they can make about the situation. The act of

Leveraging dynamic decision-making and environmental analysis to support authentic learning experiences in digital environments. Jill Stefaniak \& Meimei Xu. 
identifying assumptions pertaining to a situation enables the individual to establish boundaries for making decisions by promoting inductive reasoning (Arthur, 1994; Kahneman, 2003). This also enables the individual to make decisions within a reasonable amount of time (Gigerenzer, 2004).

Designing within a bounded rationality recognizes an individual's prior experience as being an influence on their decision-making processes (Simon, 1957). Regarding IDs, they will often conceptualize the project as it relates to their previous design projects. Design boundaries include, but are not limited to, the depth of instructional material to be covered based on the learning audience's familiarity with the topic, centering examples grounded in specific disciplines (i.e. K-12 education, higher education, or business and industry), identifying the types of learning technologies to be used to facilitate interactions among learners and promote discourse that align with the goals of the learning activity, and determining how learners will interact with an authentic learning experience through a digital platform (i.e. digital class fieldtrip, e-service-learning project, individual versus group project extended over time).

Drawing from their knowledge of the subject matter that will be implemented in the digital learning environment and instructional design practices, IDs begin to make assumptions regarding contextual factors through inductive reasoning (Arthur, 1994). The boundaries imposed by IDs allow them to examine contextual factors thoroughly which requires close attention and efforts of instructional designers. The idea of designing within a bounded rationality enables IDs to establish parameters around the project to emphasize the scope of a project. This is further supported by Baaki and Tracey's (2019) discussion on implementing a localized approach to attending to the context that can help support the time constraints often associated with dynamic decision-making in instructional situations.

When preparing to design authentic learning activities in an online environment, the instructional designer needs to operate within a bounded rationality (Simon, 1957, 1972) by imposing boundaries on their design space. These boundaries are to be determined based on an ID's prior knowledge as it relates to design in online learning environments, and their knowledge of the subject matter.

\section{Ability to Conjecture}

Designers, regardless of the design discipline, must have the confidence to conjecture and explore (Cross, 2011). While decision-making is the process of selecting a solution among several possibilities, "design conjecture is the ability to form an opinion based on constrained information and resources to design solutions that take into account systemic factors influencing an environmental context" (Stefaniak et al., 2018). The ability of IDs to mentally construct the problem space is critical to the design of a sustainable solution (Jonassen, 2000). Within their design space, IDs must impose boundaries (or constraints) on their design activity to determine how to apply various knowledge domains (i.e. conceptual, strategic, and conditional) to a specific context or situation (Paris et al., 1983; Stark et al., 2011).

Leveraging dynamic decision-making and environmental analysis to support authentic learning experiences in digital environments. Jill Stefaniak \& Meimei Xu. 
Research focused on instructional design practices reveals that it is not a linear process; rather, it is an iterative process requiring the instructional designer to engage in reflection introspection and demonstrate a level of cognitive flexibility to accommodate contextual and environmental conditions that may influence particular design decisions and solutions (Boling et al., 2011; Ertmer \& Stepich, 2005; Ertmer et al., 2008; Gibbons, 2003; Tessmer \& Wedman, 1990; Yanchar \& Gabbitas, 2011).

IDs bring prior knowledge of instructional design and the subject matter, prior experience related to instructional design practices with them to every design situation, and assumptions of the contextual factors that may influence the learning experience and overall environment. These elements that comprise an ID serve as inputs to the instructional design project and the decisionmaking that occurs during the project.

They also greatly influence IDs' abilities to conjecture about design decisions by drawing from their previous knowledge, experience, and ability to make assumptions about the design environment. The individualized skill sets that IDs provide greatly impact how they identify the types of decisions to be made during a project, how they employ decision-making strategies and the decision-making solutions they impose on the design environment.

As IDs acquire additional information that may inform their design decisions, they may revisit the different phases as needed; thus, adhering to the recursive and iterative nature of instructional design (Baaki, 2018; Klein, 2008; Tessmer \& Wedman, 1990). Throughout this conjecture process, IDs will utilize various tools to track their decision decisions (i.e. concept maps, design documents, external representations, and reflective journals). These tools will assist them with documenting and organizing information to support their design decisions through the iterative design process, thus promoting an enhanced level of cognitive flexibility (Yanchar \& Gabbitas, 2011).

\section{Alignment of Design Solutions}

Other decisions may require IDs to apply strategies while considering the long-term implications of their decisions. These types of decisions require them to understand the system they are designing within and all its moving parts. Strategic decision-making often requires IDs to make decisions informed by the context of the situation. Most, if not all, decisions made by IDs are informed by their conceptual, strategic, and conditional understanding of the field (Authors, 2019).

All instructional design decisions are made for either well-structured or ill-structured problems (Jonassen, 1997). Decision-making typically follows a discovery process or an ideaimposition process (Nutt, 2008). A discovery process is derived from prescriptions made up of steps and sequences believed to be useful. These can be likened to instructional design models commonly used in the field. The discovery process is focused on gathering information and establishing direction before making and imposing decisions. The idea-imposition process

Leveraging dynamic decision-making and environmental analysis to support authentic learning experiences in digital environments. Jill Stefaniak \& Meimei Xu. 
typically relies on a ready-made plan that gathers little intelligence, leaves directions implicit, and takes an idea-derived direction (Nutt, 2008). Regardless of the decision-making process sought, the solutions proposed by instructional designers can often be classified as ready-made versus custom (Hale et al., 2006). Ready-made solutions are fully formed and in little need of adaptation. Custom-made solutions include "alternatives that must be created for the specific situation faced" (Hale et al., p. 312).

In a study exploring how IDs engage in design conjecture (Authors 2018) found that participants who could not move beyond the problem phase of the instructional design project did not demonstrate efficacy in their abilities to make decisions with the information given. They obstructed their design process by generating reasons why design constraints would prevent them from arriving at a solution. The IDs who demonstrated increased abilities to conjecture and tolerate uncertainty associated with the project were quick to embrace an idea-imposition decision-making process (Nutt, 2008) where they focused on a ready-made solution, drawing from their previous design experiences. Examples of this would be applying a solution that they implemented in a previous project but may not have been advantageous for the current situation or context of the design problem.

The decision regarding the type of solution to be employed will be largely dependent on an ID's prior experience, their knowledge of contextual factors influencing the authentic learning experience, and their confidence to conjecture through their design decisions. This is also dependent on the length of time allocated for the learners to engage in an instructional activity, the goals of the authentic learning experience, and the expectations regarding the elicitation of conceptual, strategic, and conditional knowledge domains.

An ID's decision-making is not limited to the negotiating between discovery and ideaimposition processes or embracing a rational versus dynamic decision-making strategy; rather, it meant to be an iterative process where the designer revisits their decisions as additional information becomes available. To echo Tessmer and Wedman's (1990) sentiments regarding the iterative nature of design, we want to stress that each cycle is not meant to start the design process from the beginning. Instead, each decision-making cycle is meant to enhance the previous design to further align the design solution with the identified design constraints. McKenney and Reeves (2012) describe this iterative approach as a "deliberative-generative process that yields a wellconsidered intervention which is grounded in both theory and reality" (p. 109).

IDs who conduct environmental analyses are more apt to have the information that they need to make informed decisions and customize the authentic learning experiences that are facilitated in a digital learning environment. Information gathered from such analyses can equip instructional designers with ability to make ready-made solutions if they have designed an authentic learning experience for a similar audience in a digital environment. It also provides them with addition information to support their ability to engage in design conjecture implement custom decisions that take into account environmental factors that may greatly influence their learners 
abilities and resources to demonstrate their acquisition of conceptual, strategic, and conditional knowledge.

\section{Conclusion}

The design of learning experiences that promote the acquisition of the three above mentioned knowledge domains is guided by three constructs: environment analysis, dynamic decision-making, and promotion of knowledge acquisition. While each of these constructs contribute to decision-making in online learning environments, they are not mutually exclusive; rather, they are intertwined to promote the optimization of instructional design.

The act of decision-making encompasses IDs' abilities to conjecture, identify the types of decisions to be made for a project, and determine decision-making solutions. They must be attuned to the environmental and contextual factors that will influence their instructional design decisionmaking and their learners' acquisition of knowledge. By identifying these factors, they are better positioned to establish a bounded rationality as they design an authentic learning experience in a digital environment.

\section{Future Research}

We agree with other researchers in the field (Boschman et al., 2014; Henriksen et al., 2016; Kopcha et al., 2020; Tessmer \& Harris, 1990) that future work is needed to explore dynamic decision-making and problem-solving practices and processes in instructional design contexts. Future studies examining instructional design processes used in authentic learning contexts should place more emphasis on the strategies employed to support the design decision-making practices associated with different instructional activities. By further dissecting the rationale behind why IDs are selecting particular strategies and the internal and external conditions influencing these decisions, IDs will be better positioned on how to leverage instructional theory to accommodate different project conditions that typically present in authentic learning environments.

A multiple-faceted conceptual framework for authentic learning in digital environments will aid in the decision-making processes of IDs. More empirical studies considering the three constructive aspects within the instructional design process (i.e. environmental analysis, promotion of knowledge acquisition, and dynamic decision-making can be implemented to identify how IDs leverage contextual factors in their design decisions for authentic learning. The research exploring relationships between the instructional design decision processes, instructional design practices, and student authentic learning processes will also help us make progress toward understanding the outcomes of authentic learning in digital environments. Additionally, methods for assessing IDs' decisions to leverage environmental analysis and dynamic decision-making to support the promotion of knowledge acquisition need to be better understood.

Leveraging dynamic decision-making and environmental analysis to support authentic learning experiences in digital environments. Jill Stefaniak \& Meimei Xu. 
Although recent studies have promoted the concept of a localized context for instructional design practice where "context is scaled back to what is needed in a situation or moment" (Baaki \& Tracey, 2019, p. 1), it lacks a prescription for how to do this as well as how it can be applied across different instructional design settings. However, it does address the need for IDs to be equipped to make prompt contextualized design decisions based on available information.

It has been noted that there is a need for additional exploration into the decision-making and problem-solving processes of the instructional designer (Jonassen, 1997, 2000). To date, the role of context in instructional design practices has not extended beyond Tessmer and Richey's (1997) seminal piece exploring factors affecting the orienting, instructing, and transfer contexts. While there have been studies since then that have referenced Tessmer and Richey's view of context (Arias \& Clark, 2004; Baaki \& Tracey, 2019; Parrish, 2009; Perkins, 2003, 2008), nothing has been done to date to explore how context influences the decision-making among IDs. We know it exists, but we have yet to explore the mechanisms supporting or inhibiting decision-making performance (Sentz et al., 2019).

\section{Implications for Practice}

Authentic learning provides learners with situated learning contexts and tasks where realworld problem-solving skills can be developed (Herrington \& Oliver, 2000). Designing authentic learning experiences, therefore, is a complex and systemic process that requires IDs to understand, analyze, design, and develop authentic learning activities through environmental analysis and dynamic design decisions to promote acquisition of knowledge in real-world settings.

This paper proffers a conceptual framework to help IDs make prompt and appropriate design decisions for authentic learning in digital environments by considering environmental factors that influence design decisions. This framework reiterates that design decision-making is a constant and iterative process. Leveraging information obtained through environmental analyses informs the instructional designer's decision-making abilities and supports the design of activities grounded in an authentic context that elicit application of conceptual, strategic, and conditional knowledge domains.

We recommend that future studies in instructional design contexts can explore instructional designers' dynamic decision-making practices and processes. We also suggest that methods of assessing IDs' decisions considering the alignment between the process of environmental analysis and dynamic decision-making can be further discussed to support instructional design practices.

Although it should be noted that the alignment between IDs' abilities to engage in environmental analyses, dynamic decision-making, and the promotion of knowledge acquisition to support authentic learning in digital environments can be validated and enhanced through empirical studies, we are seeking to provide an instructional design framework for authentic learning due to the increasing demand for digital environments. Furthermore, the intentional act of aligning environmental factors with instructional activities can be of value to IDs when

Leveraging dynamic decision-making and environmental analysis to support authentic learning experiences in digital environments. Jill Stefaniak \& Meimei Xu. 
designing authentic learning experiences in a digital environment. The use and integration of different learning technologies can support IDs' abilities to provide learners with an online experience that is situated in a real-world context.

Received: March 2, 2020

Accepted: August 6, 2020

Published: September 30, 2020

Stefaniak, J. \& Xu, M. (2020). Leveraging dynamic decision-making and environmental analysis to support authentic learning experiences in digital environments. RED. Revista Educación a Distancia, 20(64). http://dx.doi.org/10.6018/red.412171

\section{Funding}

This research has not received any specific grant from funding agencies in the public, commercial or non-profit sectors.

\section{References}

Al Mamun, M. A., Lawrie, G., \& Wright, T. (2020). Instructional design of scaffolded online learning modules for self-directed and inquiry-based learning environments. Computers \& Education, 144, 103695.

Anak Marcus, V. B., Atan, N. A., Jumaat, N. F., Junaidi, J., \& Said, M. N. H. M. (2018). Improving student's learning outcomes through e-service learning based on authentic learning strategy. Innovative Teaching and Learning Journal, 2(1), 8-16.

Arias, S., \& Clark, K. A. (2004). Instructional technologies in developing countries: A contextual analysis approach. TechTrends, 48(4), 52-55.

Arthur, W. B. (1994). Inductive reasoning and bounded rationality. The American Economic Review, 84(2), 406-411.

Baaki, J. (2018). Tessmer and Wedman: Ahead of their time. Journal of Applied Instructional Design, 7(2), 17-20.

Baaki, J., \& Tracey, M.W. (2019). Weaving a localized context of use: What it means for instructional design. Journal of Applied Instructional Design, 8(1), 1-13.

Barsalou, L. W. (2015). Situated conceptualization: Theory and applications. In Y. Coello \& M. H. Fischer (Eds.), Perceptual and emotional embodiment: Foundations of embodied cognition (pp. 19-45). Routledge.

Bloom, B.S. (1956). Taxonomy of educational objectives: The classification of educational goals, Handbook I: Cognitive domain. New York, NY: David McKay Company, Inc.

Boling, E., Easterling, W. V., Hardré, P. L., Howard, C. D., \& Roman, T. A. (2011). ADDIE: Perspectives in transition. Educational Technology, 34-38.

Leveraging dynamic decision-making and environmental analysis to support authentic learning experiences in digital environments. Jill Stefaniak \& Meimei Xu. 
Boschman, F., McKenney, S., \& Voogt, J. (2014). Understanding decision making in teachers' curriculum design approaches. Educational Technology Research and Development, 62(4), 393-416.

Broadbent, J., \& Poon, W. L. (2015). Self-regulated learning strategies \& academic achievement in online higher education learning environments: A systematic review. The Internet and Higher Education, 27, 1-13.

Callison, D., \& Lamb, A. (2004). Key words in instruction: Authentic learning. School Library Media Activities Monthly, 21(4), 34-39.

Cross, N. (2011). Design thinking. New York, NY: Berg.

Cui, G., Lockee, B., \& Meng, C. (2013). Building modern online social presence: A review ofsocial presence theory and its instructional design implications for future trends. Education and information technologies, 18(4), 661-685.

De Martino, B., Kumaran, D., Seymour, B., \& Dolan, R. J. (2006). Frames, biases, and rational decision-making in the human brain. Science, 313(5787), 684-687.

Ertmer, P. A., \& Cennamo, K. S. (1995). Teaching instructional design: An apprenticeship model. Performance improvement quarterly, 8(4), 43-58.

Ertmer, P. A., \& Koehler, A. A. (2014). Online case-based discussions: Examining coverage of the afforded problem space. Educational Technology Research and Development, 62(5), 617-636.

Ertmer, P. A., Sadaf, A., \& Ertmer, D. J. (2011). Student-content interactions in online courses: The role of question prompts in facilitating higher-level engagement with course content. Journal of Computing in Higher Education, 23(2-3), 157.

Ertmer, P. A., \& Stepich, D. A. (2005). Instructional design expertise: How will we know it when we see it? Educational Technology, 45(5), 38-43.

Ertmer, P.A., Stepich, D.A., York, C., S., Stickman, A., Wu, X.L., Zurek, S., \& Goktas, Y. (2008). How instructional design experts use knowledge and experience to solve ill structured problems. Performance Improvement Quarterly, 21(1), 17-42.

Gagne, R.M. (1964). Problem solving. In A.W. Melton (Ed.), Categories of human learning (pp. 293-317). New York, NY: Academic Press.

Gagne, R.M., \& Merrill, M.D. (1990). Integrative goals for instructional design. Educational Technology Research and Development, 38(1), 23-30.

García-Cabrero, B., Hoover, M. L., Lajoie, S. P., Andrade-Santoyo, N. L., Quevedo-Rodríguez, L. M., \& Wong, J. (2018). Design of a learning-centered online environment: a cognitive apprenticeship approach. Educational Technology Research and Development, 66(3), 813835.

Gibbons, A. S. (2003). What and how do designers design? TechTrends, 47(5), 22-27.

Gigerenzer, G. (2004). Fast and frugal heuristics: The tools of bounded rationality. In D.J. Koehler \& N. Harvey (Eds.), Blackwell handbook of judgment and decision making (pp.62-88). New York, NY: Wiley \& Sons.

Leveraging dynamic decision-making and environmental analysis to support authentic learning experiences in digital environments. Jill Stefaniak \& Meimei Xu. 
Gillett-Swan, J. (2017). The challenges of online learning: Supporting and engaging the isolated learner. Journal of Learning Design, 10(1), 20-30.

Gray, C. M., Dagli, C., Demiral-Uzan, M., Ergulec, F., Tan, V., Altuwaijri, A. A., Gyabak, K., Hilligoss, M., Kizilboga, R., Tomita, K., \& Boling, E. (2015). Judgment and instructional design: How ID practitioners work in practice. Performance Improvement Quarterly, 28(3), 25-49.

Greenhow, C., Robelia, B., \& Hughes, J. E. (2009). Learning, teaching, and scholarship in a digital age: Web 2.0 and classroom research: What path should we take now?.Educational Researcher, 38(4), 246-259.

Hale, J. E., Hale, D. P., \& Dulek, R. E. (2006). Decision processes during crisis response: An exploratory investigation. Journal of managerial issues, 301-320.

Henriksen, D., Mishra, P., \& Fisser, P. (2016). Infusing creativity and technology in 21 st century education: A systemic view for change. Educational Technology \& Society, 19(3), 27-37.

Herrington, J. (2006, October). Authentic e-learning in higher education: Design principles for authentic learning environments and tasks. In E-Learn: World Conference on E-Learning in Corporate, Government, Healthcare, and Higher Education (pp. 3164-3173). Association for the Advancement of Computing in Education (AACE).

Herrington, J., \& Oliver, R. (2000). An instructional design framework for authentic learning environments. Educational Technology Research and Development, 48(3), 23-48.

Herrington, J., Oliver, R., \& Reeves, T. C. (2003). Patterns of engagement in authentic online learning environments. Australasian Journal of Educational Technology, 19(1).

Herrington, J., \& Parker, J. (2013). Emerging technologies as cognitive tools for authentic learning. British Journal of Educational Technology, 44(4), 607-615.

Herrington, J., Reeves, T. C., \& Oliver, R. (2014). Authentic learning environments. In Handbook of research on educational communications and technology (pp. 401-412). Springer.

Herrington, J., Reeves, T. C., \& Oliver, R. (2007). Immersive learning technologies: Realism and online authentic learning. Journal of Computing in Higher Education, 19(1), 80-99.

Jenkins, H., Putushotma, R., Weigel, M., Clinton, K., \& Robison, A. (2009). Confronting the challenges of participatory culture: Media education for the $21^{\text {st }}$ century. MIT Press.

Jonassen, D.H. (1997). Instructional design model for well-structured and ill-structured problemsolving learning outcomes. Educational Technology Research and Development, 45(1), 6595.

Jonassen, D.H. (2000). Toward a design theory of problem solving. Educational Technology Research and Development, 48(4), 63-85.

Jonassen, D. H. (2010). Learning to solve problems: A handbook for designing problem-solving learning environments. New York, NY: Routledge.

Jonassen, D. H. (2012). Designing for decision making. Educational Technology Research and Development, 60(2), 341-359.

Leveraging dynamic decision-making and environmental analysis to support authentic learning experiences in digital environments. Jill Stefaniak \& Meimei Xu. 
Kahneman, D. (2003). A perspective on judgment and choice: mapping bounded rationality. American Psychologist, 58(9), 697-720.

Keengwe, J., \& Kidd, T. T. (2010). Towards best practices in online learning and teaching in higher education. MERLOT Journal of Online Learning and Teaching, 6(2), 533-541.

Kim, R., Olfman, L., Ryan, T., \& Eryilmaz, E. (2014). Leveraging a personalized system to improve self-directed learning in online educational environments. Computers \& Education, 70, 150-160.

Klein, G. (2008). Naturalistic decision making. Human Factors, 50(3), 456-460.

Kopcha, T. J., Neumann, K. L., Ottenbreit-Leftwich, A., \& Pitman, E. (2020). Process over product: The next evolution of our quest for technology integration. Educational Technology Research and Development, 68(2), 729-749.

Lai, P. K., Portolese, A., \& Jacobson, M. J. (2017). Does sequence matter? Productive failureand designing online authentic learning for process engineering. British Journal of Educational Technology, 48(6), 1217-1227.

Lau, U. H., \& Tasir, Z. (2018). The design and development of online authentic learning environment for knowledge construction in learning inferential statistics. The Journal of Social Sciences Research, 71-79.

Luo, H., Koszalka, T. A., Arnone, M. P., \& Choi, I. (2018). Applying case-based method in designing self-directed online instruction: a formative research study. Educational Technology Research and Development, 66(2), 515-544.

Martin, C. K., Nacu, D., \& Pinkard, N. (2016). Revealing opportunities for 21st century learning: An approach to interpreting user trace log data. Journal of Learning Analytics, 3(2), 37-87.

McKenney, S., \& Reeves, T.C. (2012). Conducting educational design research. Routledge.

Meloncon, L.K. (2017). Patient experience design: Expanding usability methodologies for healthcare. Communication Design Quarterly, 5(2), 20-28.

Merrill, M.D. (1999). Instructional transaction theory. In C.M. Reigeluth (Ed.), Instructional design theories and models: An overview of their current status (pp. 279-333). Lawrence Erlbaum Associates.

Nacu, D., Martin, C. K., \& Pinkard, N. (2018). Designing for 21st century learning online: a heuristic method to enable educator learning support roles. Educational Technology Research and Development, 66(4), 1029-1049.

Nelson, H. G., \& Stolterman, E. (2000). The case for design: Creating a culture of intention. Educational Technology, 40(6), 29-35.

Nutt, P.C. (2008). Investigating the success of decision-making processes. Journal of Management Studies, 45(2), 425-455.

Paris, S.G., Lipson, M.Y., \& Wixson, K.K. (1983). Becoming a strategic reader. Contemporary Educational Psychology, 8, 293-316.

Parker, J., Maor, D., \& Herrington, J. (2013). Authentic online learning: Aligning learner needs, pedagogy and technology. Issues in Educational Research, 23(2), 227.

Leveraging dynamic decision-making and environmental analysis to support authentic learning experiences in digital environments. Jill Stefaniak \& Meimei Xu. 
Parrish, P. E. (2009). Aesthetic principles for instructional design. Educational Technology Research and Development, 57, 511-528.

Partnership for $21^{\text {st }}$ Century Learning. (2016). Framework for $21^{\text {st }}$ century learning. http://www.p21.org/storage/documents/docs/P21_framework_0816.pdf

Perkins, R. A. (2003). The role of context in instructional design: A case study examining the repurposing of Web-based master's degree courses for use in Malawi (Doctoral dissertation, Virginia Tech).

Perkins, R. A. (2008). Challenges and questions concerning "culturally-sensitive design." TechTrends, 52(6), 19-21.

Rabel, D. K. (2019). An examination of the decision-making process instructional designers use to complete projects with the constraints of limited time and tools (Doctoral Dissertation). Available from Old Dominion University Digital Commons at https://digitalcommons.odu.edu/stemps_etds/107

Rashid, T., \& Asghar, H. M. (2016). Technology use, self-directed learning, student engagement and academic performance: Examining the interrelations. Computers in Human Behavior, 63, 604-612.

Richardson, J. C., Maeda, Y., Lv, J., \& Caskurlu, S. (2017). Social presence in relation to students' satisfaction and learning in the online environment: A meta-analysis. Computers in Human Behavior, 71, 402-417.

Richardson, J. C., Sadaf, A., \& Ertmer, P. A. (2013). Relationship between types of question prompts and critical thinking in online discussions. In Educational communities of inquiry: Theoretical framework, research and practice (pp. 197-222). Hershey, PA: IGI Global.

Richey, R.C., \& Tessmer, M. (1995). Enhancing instructional systems design through contextual analysis. In B.B. Seels (Ed.), Instructional design fundamentals: A reconsideration (pp. 189-199). Educational Technology Publications.

Rule, A. C. (2006). The components of authentic learning. Journal of Authentic Learning, 3(1), 110.

Sanga, M. W. (2017). Closing gap between learning and use: Operationalizing the situated cognition construct to create authentic online learning contexts. The Online Journal of Distance Education and E-Learning, Contents, 5(3).

Sentz, J., \& Stefaniak, J. (2019). Instructional heuristics for the use of worked examples to manage instructional designers' cognitive load while problemsolving. TechTrends, 63(2), 209-225.

Sentz, J., Stefaniak, J., Baaki, J., \& Eckhoff, A. (2019). How do instructional designers manage learners' cognitive load? An examination of awareness and application of strategies. Educational Technology Research and Development, 67(1), 199-245.

Sharma, P., \& Hannafin, M. (2004). Scaffolding critical thinking in an online course: An exploratory study. Journal of Educational Computing Research, 31(2), 181-208.

Simon, H.A. (1957). Models of man. New York, NY: Wiley \& Sons.

Simon, H. A. (1972). Theories of bounded rationality. Decision and Organization, 1(1), 161-176.

Leveraging dynamic decision-making and environmental analysis to support authentic learning experiences in digital environments. Jill Stefaniak \& Meimei Xu. 
Spector, J. M. (2018). Future trends of designing learning in the global context. In Authentic Learning Through Advances in Technologies (pp. 205-216). Springer.

Stark, R., Kopp, V., \& Fischer, M. R. (2011). Case-based learning with worked examples in complex domains: Two experimental studies in undergraduate medical education. Learning and Instruction, 21(1), 22-33.

Stefaniak, J. E. (2017). The role of coaching within the context of instructional design. TechTrends, 61(1), 26-31.

Stefaniak, J. (2020a). The Utility of Design Thinking to Promote Systemic Instructional Design Practices in the Workplace. TechTrends, 64(2), 202-210.

Stefaniak, J. (2020b). A Systems View of Supporting the Transfer of Learning through E-ServiceLearning Experiences in Real-World Contexts. TechTrends, 64(4), 561-569.

Stefaniak, J. (2021). Needs assessment for learning and performance: Theory, process, and practice. Routledge.

Stefaniak, J., Baaki, J., Hoard, B., \& Stapleton, L. (2018). The influence of perceived constraints during needs assessment on design conjecture. Journal of Computing in Higher Education, 30(1), 55-71.

Stefaniak, J. E., \& Tracey, M. W. (2014). An examination of the decision-making process used by designers in multiple disciplines. TechTrends, 58(5), 80-89.

Tessmer, M. (1990). Environment analysis: A neglected stage of instructional design. Educational Technology Research and Development, 38(1), 55-64.

Tessmer, M., \& Wedman, J. F. (1990). A layers-of-necessity instructional development model. Educational Technology Research and Development, 38(2), 77-85.

Tessmer, M. (1991). Back to the future: The environment analysis stage of front-end analysis. Performance and instruction, 30(1), 9-12.

Tessmer, M., \& Richey, R. C. (1997). The role of context in learning and instructional design. Educational Technology Research and Development, 45(2), 85-115.

Tessmer, M., \& Wedman, J. (1995). Context-sensitive instructional design models: A response to design research, studies, and criticism. Performance Improvement Quarterly, 8(3), 38-54.

Yanchar, S. C., \& Gabbitas, B. W. (2011). Between eclecticism and orthodoxy in instructional design. Educational Technology Research and Development, 59(3), 383-398.

Yanchar, S. C., \& Hawkley, M. (2014). "There's got to be a better way to do this": a qualitative investigation of informal learning among instructional designers. Educational Technology Research and Development, 62(3), 271-291.

Yanchar, S. C., South, J. B., Williams, D. D., Allen, S., \& Wilson, B. G. (2010). Struggling with theory? A qualitative investigation of conceptual tool use in instructional design. Educational Technology Research and Development, 58(1), 39-60.

Zhu, M., Basdogan, M., \& Bonk, C. J. (2020). A case study of the design practices and judgments of novice instructional designers. Contemporary Educational Technology, 12(2), ep267.

Leveraging dynamic decision-making and environmental analysis to support authentic learning experiences in digital environments. Jill Stefaniak \& Meimei Xu. 